\title{
Value Network of Amazon Non Timber Forest Products: A Mapping Tool to Support a Complex Network Strategic Planning
}

\author{
Jeferson Straatmann, Mateus Cecílio Gerolamo, and Luiz Cesar Ribeiro Carpinetti \\ School of Engineering of São Carlos, University of São Paulo, Av. Trabalhador Sancarlense, \\ 400, São Carlos - SP, CEP.: 13566-590, Brazil \\ jstraatmann@gmail.com
}

\begin{abstract}
The Non Timber Forest Products (NTFP) value chains are viewed as an alternative for the forest conservation and for the improvement of life conditions of Traditional Communities. These products are part of different chemical, cosmetic, food and pharmaceutical industries, which are trying to improve the sustainability of their supply chains. For the improvement of interorganizational NTFP network in the Amazon region, an adapted value chain map was structured to map the Value Network and foster the strategic planning process. The mapping tool brought the whole scenario view for planning process, helping to integrate knowledge, values and perspectives, resulting in a common view for the NTFP Value Network future.
\end{abstract}

Keywords: Value Chain Mapping, Inter-organizational Network, Collaborative Network, Value Network Mapping, Non Timber Forest Products, Rural and Forest SMEs.

\section{Introduction}

The market demand for organic products and for social-environmental safe products is increasing worldwide and companies are no longer ignoring these issues [1]. To deliver the quality demanded for those products the companies must take deeply care of their value chain, with a good traceability process implemented and, in some cases, to work closely with suppliers. That is especially relevant in the Non Timber Forest Products (NTFP) scenario.

In Brazil, mainly in the Amazon Forest, the NTFP are usually not domesticated species, collected directly from the forest by Traditional Population/Communities ${ }^{1}$ (Indigenous, Riverside, Maroons) [3]. The harvesting of these products demands a huge effort from the population, being made in a rudimentary/low technology mean and commercialized to different levels of middlemen [4]. Due to the dispersion in the

1 According to the Brazilian government law for Traditional Population / Community, Traditional Population are: culturally diverse groups that are recognized as such, with their own forms of social organization, which occupy and use lands and natural resources as a condition to its cultural, social, religious, ancestral and economic, knowledge, innovations and practices, generated and transmitted by tradition [2]. 
Amazon territory, the seasonality, the infrastructure issues and low volume of production it is difficult for companies to have only one supplier, requiring a network of suppliers. This process requires a great coordination effort from companies that usually prefer to purchase their forest raw material from middlemen.

After the ECO 92 conference the attentions for the NTFP value chains and for the Traditional Communities start to grow, increasing the government investments in the creation of new sustainable use protected areas, increasing, also, the number of Non Governmental Organizations (NGO), international agencies and government environmental institutions [5]. That has promoted a strong socio-environmental network, with many inter-dependent institutions, generally with a low coordination level in different regions. Usually these institutions participate directly or indirectly in the promotion of NTFP value chains, but with low contact with market reality, technology, and enterprises demand.

The Brazilian Amazon Forest is a traditional source of raw materials for food, cosmetics and pharmaceutical enterprises, which have usually two possibilities: $i$ ) buy NTFP from the "exploiting" supply chain [4, 6]; or, ii) promote specific agreements and partnerships with Traditional Communities $[6,7]$. The agreement between The Body Shop Company and Kayapó Indigenous Communities in Brazilian Pará State, for purchasing Brazilian Nut Oil, is an example of a dyadic relationship between a cosmetic enterprise and a Traditional Community [6, 7]. The agreement was continuously supported by The Body Shop and FUNAI (the Brazilian government indigenous agency), but it did not work properly for a number of not well considered factors, specially: $i$ ) the Kaypó traditional way of life (social organization, subsistence agriculture, volumes, forest multiple use) and, ii) the involvement of important regional institutions, that could have provided support, added value and transparency to the partnership. To escape from those simple dyadic "business" relationships the companies, institutions and Traditional Communities must start to see the Product Value Chain as a Product Value Network, which sees more than just the chain relations but specially add value through the horizontal network perspective.

The value added in the product network may appear to the market in terms of a better communication between the chain "direct/productive" actors (Traditional Communities, traders, enterprises), and the "indirect" actors (government agencies, NGOs, sponsors), increasing knowledge, trust, trade transparency, quality, traceability for the whole network and consumers.

The organization and visualization of the Value Network data for a regional NTFP strategic planning process - involving different actors (some analphabets) - is a complex and challenge activity. The paper brings the adaptation made in two value chain mapping process to structure a Value Network Map (VNM), and a case description of a NTFP Value Network strategic planning process at Altamira region in the Brazilian Amazon.

This specific tool provides a simple graphical display of the vertical network (between the value chain links), also presenting information about the horizontal network (Traditional Communities networks and support institutions networks). A scenario analysis combining the mapping tool with network and planning methods were used for the strategic planning process. The methods used, its adaptation for the local reality, the process and the results obtained are described. 
This paper is organized as follows: section 2 presents a review of Value Stream Mapping, Value Links and describes the adaptation in the methods to satisfy the Network demand; section 3 presents and discuss the application of the tool for a specific Network Strategic Plan in the Amazon region; section 4 conclude this work.

\section{Value Chain Mapping and Analysis}

Different processes mapping tools can be used for mapping the value chain of a product. The Value Stream Mapping (VSM) was developed and is being used for improvement of internal and external streams or chains of industries (mainly autoparts) $[8,9]$. Its visual characteristics were designed to be easily understandable for the whole company, from the shop floor employees to the company CEOs. This specific aspect of the VSM is particularly appropriated to NTFP chains context that involves: Traditional Communities (high illiteracy rate), social institutions, government and enterprises.

Because of the original use, oriented for manufacture enterprises, the VSM is able to well organize productive, logistics, market and production methods data and indicators $[8,9]$. This tool competence provides a well structured mean to organize and see the chain in detail, with different information and comparing one process or chain operator with the others. The VSM is oriented for the improvement of selected product chains, not being able to provide the visualization of the Network as a whole (value chain operators, stakeholders and support actors).

This Stakeholders complementation is better organized in the ValueLinks Mapping (VLM) tool, developed by GTZ (German Agency for Technical Cooperation) to promote specific micro and small-sized enterprises, small farmers, agribusiness, handicraft or manufacturing sub-sectors by promoting the value chains they are operating in [10]. But, nevertheless, the methodology focus continues in the analysis of a specific chain.

The ValueLinks method is oriented to promote diverse kinds of rural value chains, considering the Micro level (the value chain operators and the operational service providers) and the Meso level (includes all chain-specific actors providing regular support services or representing the common interest of the value chain actors) [10]. The analysis is grouped in three main tasks, being the mapping of the value chain the most essential one: i) Value chain mapping; ii) Quantifying and describing value chains in detail; iii) Economic analysis of value chains and benchmarking.

The organization and visualization of the VLM is done mainly by boxes structures, linked by arrows and oriented by the value chain processes. The graphical standard is basically the same for the different operators, not providing a clear picture for logistics issues and the processes itself. The Meso level visualization of the VLM (inferior part of the map - Fig. 1) and the participative methodology brings a good complementation to the VSM.

An integration of both methods (Fig. 1) allows a good graphic quality of the chain, with easy understandability, a participative analysis of the process and the visualization of the stakeholders. This integration can be strengthened with the vision of the inter-organizational network as a whole, which reinforce the necessity of a 
perspective change: from a value chain to a value network, defined as a set of relatively autonomous units, managed independently, operating together in a framework of common principles and service level agreements [11, 12], including the chain operators, the support institutions and stakeholders.

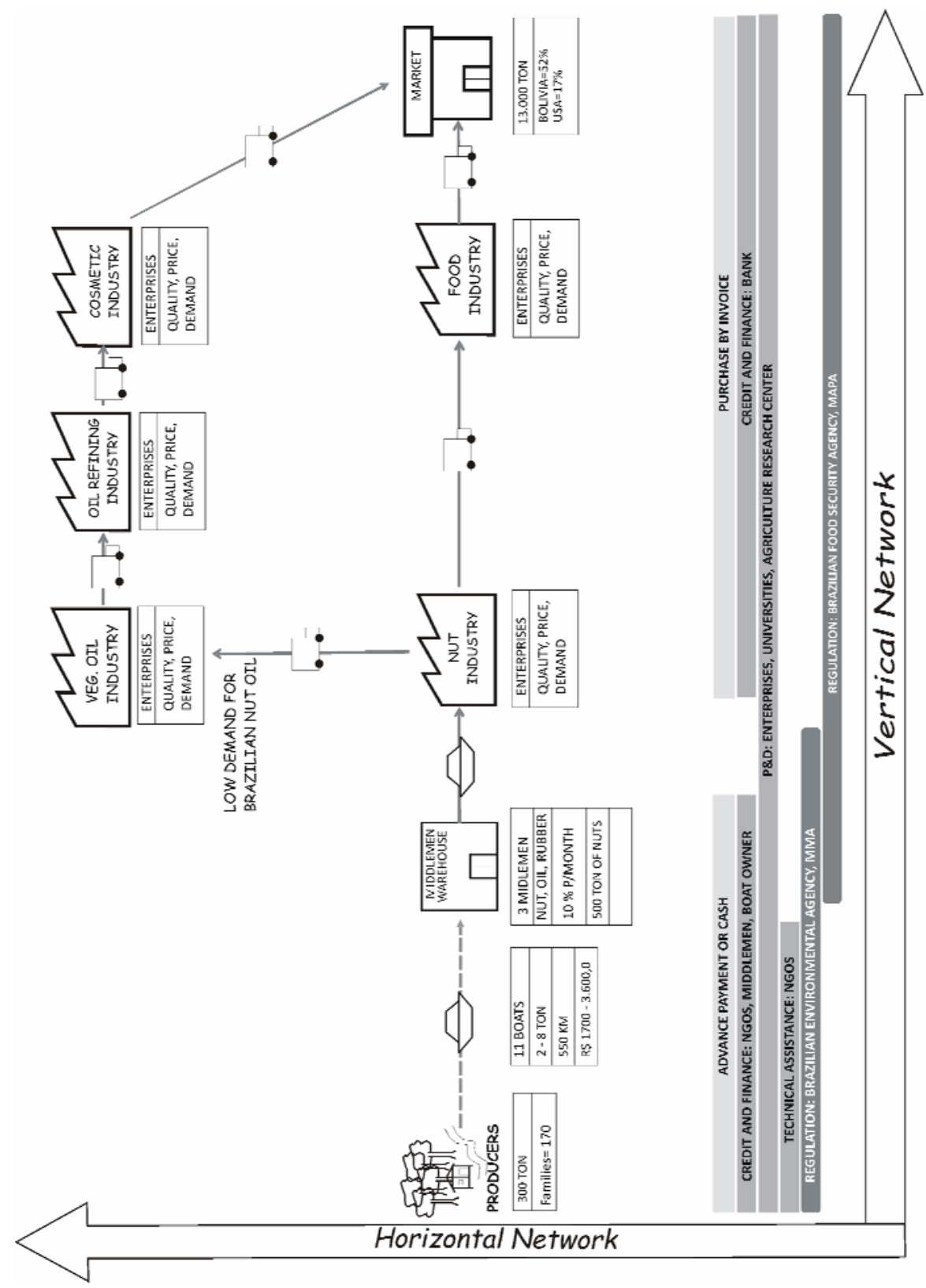

Fig. 1. Brazilian Nuts Value Network Map 
For the Amazon NTFP, the perspective change from value chain to value network is a gain of quality in action, due to different regional bottlenecks, like: the disperse and informal network of Traditional Communities; the lack of communication forms in the region; the bad logistics infrastructure; the "preference" for "exploratory" commercialization chains to reduce purchasing costs; and, the lack of coordination between governmental agencies, enterprises and NGOs.

Other tools should be used concomitantly to support the VNM, the planning process and the common future statement, specially: market, logistics, infrastructure and statistics data, Wenn diagram, SWOT analysis, World Café and Appreciative Inquiry. The last two methods are centered in the persons (experiences and perspectives), searching individual and common group goals/visions for cooperation in the specific work environment (enterprise, network, etc.).

\section{NTFP Collaborative Network Strategic Planning}

The Altamira municipality is located in the Pará state, inside the Brazilian Amazon. Most of the region is surrounded by protected areas, created mainly in the last decade (2000 - 2010) to protect the forest and the Traditional Communities of the region (mainly riverside communities and indigenous communities) as a result of different inter-organizational work. The use of these areas are restricted, some of which are full protected areas (only scientific research is allowed) and some are intended for living and for sustainable use. That directs the regional potential for forest entrepreneurship, specifically NTFPs for the Traditional Communities.

There are different kinds and levels of networks in the region, structuring, sharing knowledge and labor force in different scenarios. Inside the sustainable use protected areas the social organization are structured in familiar and social networks, that change knowledge about the best practices of managing the forest, change work force for the bottlenecks activities and provides assistance for emergency issues. These networks are connected to a formal organization that represents the protected area population. Usually these formal organizational standards do not represent the population organizational forms, which complicate its management.

The regional institutions, including the Traditional Communities ones, are organized in an informal network, to dialog, plan and act in a more coordinated way. This network was formed in 2008 to organize the diverse organizations in the regions to face the social, environmental and economics regional challenges. The network has specific cliques or sub-networks of institutions that are focused in their specific goals, being the NTFPs clique an important part of it.

The Wenn Diagram in Fig. 2 illustrates the organizational scenario of the region regarding the NTFPs. The proximity to the center illustrates the activeness and importance of the player, classifying actors as: $i$ ) with Veto power (V); ii) first, second and third layer player; and, iii) Enterprise, Government and NGO player. The lines qualifies the kind of relationship between the actors: $i$ ) continuous line - stable relationship; ii) dashed line - weak relationship; iii) double line - strong relationship; iv) lightning - conflict; and, v) continues line with stroke - relationship stopped. 


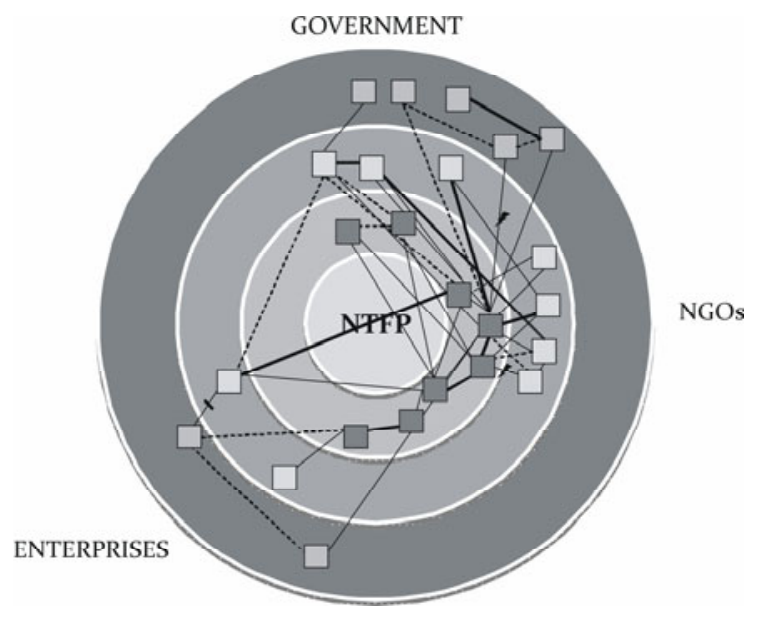

Fig. 2. Wenn Diagram for NTFP in the studied region

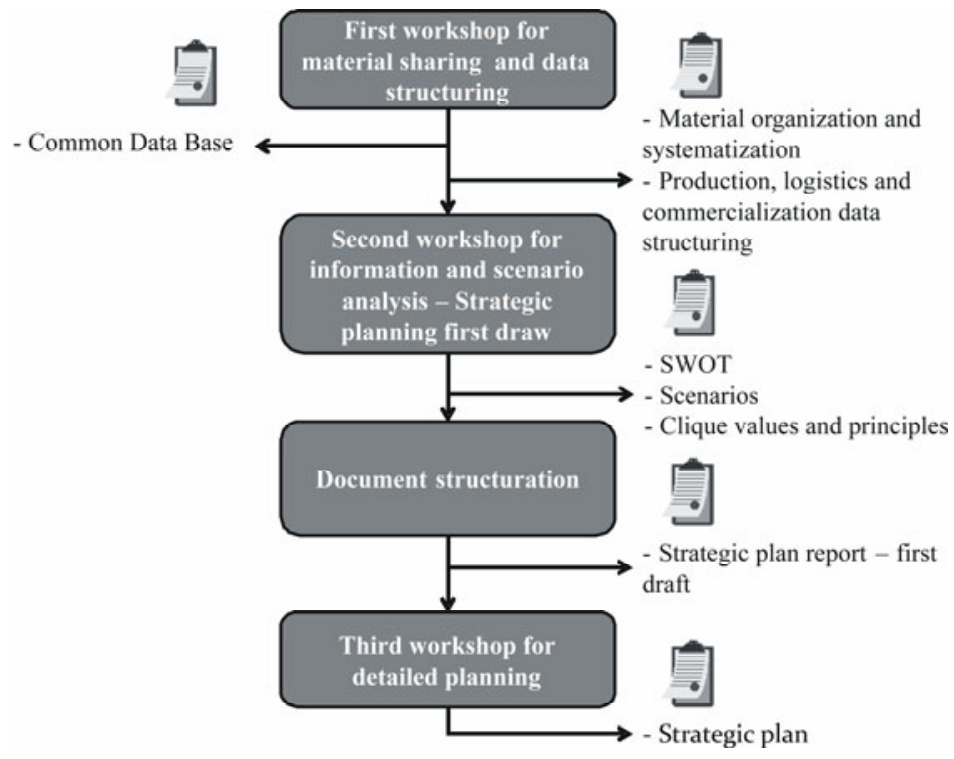

Fig. 3. Planning process and results

This NTFP clique is improving the network organization, promoting a strategic planning process to guide the clique actions and influencing the regional political scenario. The process were structured in four planning phases, mainly focused in: $i$ ) knowledge sharing and structuring; ii) scenario and SWOT analysis and common values, principles and goals statement; iii) information and documentation structuring; and $i v$ ) detailed planning (Fig. 3).

The whole strategic plan process was oriented by the Value Network Map structured as showed in section 2 of this paper. The map promoted a better 
understanding of the whole network (vertical and horizontal actors), facilitating the dialog between Traditional Communities, supporting institutions and partner enterprises. The production, logistics and commercialization data (gathered in the first phase) was structured in the map and additional support worksheets and maps was prepared. The tool brings a better understanding of the current scenario of NTFPs in the region, helping to answer some questions about cooperation and improvement of value networks: how are the relationships between the actors of the chain (producers, middlemen, local retailers, industrial partner)? What public polices could be accessed and what is missing for that happens? What are the fair prices for NTFP in different situations? How does the commercialization processes works for the communities and for the industrial partners? What arrangements should be done for improvements? How to improve the Traditional Communities networks exchanges (knowledge, process standards, processing tools and equipments)? What strategy should be followed to add value to the NTFP and when (outsource production? attract companies to the region? organize business partnerships? Etc.)?

The SWOT analysis was developed just after the map construction and explanation, resulting in different evaluations of the current scenario. A scenario analysis using the Value Network Map and the SWOT results was performed thereafter, revealing the cooperation necessity within the different actors, resulting in different collective actions such as: common data base of materials; common plan for NTFPs; land regularization processes; institutions technicians join training process; NTFPs quality processes standards; regional socio-environmental quality label for NTFPs; public policies for production and commercialization shared actions; and, mapping of the existing Traditional Communities networks and relationships.

An important result and input for the process was the creation of common values, principles and goals for the network clique. This perspective arrives to solve dialog issues between the actors, which were too much focused in their own institutions goals, creating barriers for the planning processes. The common values were important to align the perspectives of the participants/organizations and foster productive and shared dialogs.

Aiming the improvement of the relationships and the commitment with the plan, the final workshop was structured with the combination of two common future statement methodologies: Appreciative Inquiry and World Café. These methodologies improved the understanding of the proposals, reinforced the common goals, values and principles of the clique and fostered the individual commitment with the collective plan. The final workshop reviewed the decisions taken in the scenario analysis, prioritized the actions, and determined the responsible parties, resources and deadlines.

\section{Conclusion}

The combination of the VSM and ValueLinks tools to map the Value Network provided good results for the NTFPs planning process, providing in terms of representation: a structured data organization, especially for the chain operators in the dialog box; a better understanding of the connection and ties between the chain operators; the position of the stakeholders (support, credits, technical and regulatory institutions in the chain). Concerning the planning process the tool provided: 
knowledge exchange; the whole network understanding; a better analysis of the current and future scenarios; commitment; and, a clearer definition of bottlenecks, roles, common goals, collective actions and future vision.

The improvement/adaptation of the mapping tool, a reorganization of the process and the utilization of complementary planning tools are recommended, according to the inter-organizational network context. For the specific case of NTFPs it is strongly recommended to adopt a Value Chain and/or Value Network Mapping Tool to organize the vertical and horizontal cooperation data, allowing actors to see the whole instead of their limited organizational scope.

Future research may be conducted especially concerning: i) Full Development/ Improvement of the Value Network Mapping Tool and detailed framework; ii) research over inter-organizational collaborative meetings methodologies for common future statement, like World Café and Appreciative Inquiry; and, iii) research over network planning frameworks.

\section{References}

1. Butler, R., Laurance, W.F.: New strategies for conserving tropical forests. Trends in Ecology \& Evolution 23(9), 469-472 (2008)

2. Brasil: Decreto No 6.040, de 7 de fevereiro de 2007. Institui a Política Nacional de Desenvolvimento Sustentável dos Povos e Comunidades Tradicionais (2007)

3. Homma, A.K.O.: The dynamics of extraction in Amazonia: A historical perspective. In: Nepstad, D.C., Schwartzman, S. (eds.) Non-timber Products from Tropical Forests: Evaluation of a Conservation and Development Strategy. Advances in Economic Botany, vol. 9, pp. 23-32 (1992)

4. Belcher, B., Schreckenberg, K.: NTFP Commercialization: A Reality Check. Development Policy Review 25(3), 355-377 (2007)

5. Fearnside, P.M.: Conservation Policy in Brazilian Amazonia: Understanding the Dilemmas. World Development 31(5), 757-779 (2003)

6. Ros-Tonen, M.A.F., Andel, T.V., Morsello, C., Otsuki, K., Rosendo, S., Scholz, I.: Forestrelated partnerships in Brazilian Amazonia: There is more to sustainable forest management than reduced impact logging. Forest Ecology and Management 256, 1482-1497 (2008)

7. Morsello, C.: Company-community non-timber forest product deals in the Brazilian Amazon: A review of opportunities and problems. Forest Policy and Economics 8(4), 458 494 (2006)

8. Rother, M., Shook, J.: Learn to See: Value Stream Mapping to Add Value and Eliminate MUDA. Lean Enterprise Institute, Cambridge (1999)

9. Jones, D., Womack, J.: Seeing the Whole: mapping the extended value stream. Lean Enterprise Institute, Cambridge (2002)

10. Springer-Heinze, A. (ed.): ValueLinks Manual - The Methodology of Value Chain Promotion. GTZ, Eschborn (2007),

http: / /www.value-links.de/manual/distributor.html (Access at: April 11, 2011)

11. Ehret, M.: Managing the trade-off between relationships and value networks. Towards a value-based approach of customer relationship management in business-to-business markets. Industrial Marketing 33, 465-473 (2004)

12. Peppard, J., Rylander, A.: From Value Chain to Value Networks: Insights for mobile operators. European Management Journal 24(2-3), 128-141 (2006) 